Revista de Derecho

\title{
Análisis comparado del hábeas corpus en Bolivia, Colombia y Ecuador
}

Comparative Analysis of Habeas Corpus in Bolivia, Colombia and Ecuador

\section{Camilo Emanuel Pinos Jaén}

Docente de la Universidad Católica de Cuenca, Sede Azogues

Cuenca, Ecuador

cpinosj@ucacue.edu.ec

ORCID: 0000-0002-0934-8471

Artículo de investigación

DOI: https://doi.org/10.32719/26312484.2022.37.7

Fecha de recepción: 29 de junio de 2021

Fecha de revisión: 31 de agosto de 2021

Fecha de aceptación: 15 de septiembre de 2021

Fecha de publicación: 3 de enero de 2022 


\section{RESUMEN}

La presente investigación aborda el estado actual del hábeas corpus en Ecuador y Colombia, así como la acción de libertad en Bolivia, establecida como un derecho y garantía jurisdiccional. Considerando su evolución a lo largo de la historia, se realizó un recorrido cronológico por Roma, Inglaterra, España y en algunos países de Latinoamérica con el objeto de entender la necesidad de su reconocimiento en el ordenamiento jurídico de cada Estado.

Para ello, luego de identificar su reconocimiento constitucional, se analizó el objeto, ámbito de protección y la realidad procesal en que opera, a partir del estudio de las disposiciones jurídicas y normas de cada Estado; así como también el desarrollo jurisprudencial de sus máximas instituciones de administración de justicia constitucional, conocidas como órganos de cierre en la materia.

En este sentido, se pudo reconocer los derechos que principalmente se protegen a través de esta garantía, como por ejemplo la libertad ambulatoria, la integridad física, y la vida; sin embargo, existen derechos conexos como la salud, la dignidad, por citar, que también se encuentran tutelados, lo cual, varía según el Estado en análisis. Finalmente, a más de establecer similitudes y diferencias, se pudo encontrar algunos problemas y desafíos del hábeas corpus y acción de libertad, que, de cierta forma, limitan una mayor eficacia en la praxis.

PALABRAS CLAVE: hábeas corpus; acción de libertad; garantía constitucional; acción; tipología; análisis comparado; desafíos; desarrollo jurisprudencial.

\section{ABSTRACT}

This research addresses the current state of habeas corpus in Ecuador and Colombia, as well as the liberty action in Bolivia, established as a right and jurisdictional guarantee. Considering its evolution throughout history, a chronological route of Rome, England, Spain and in some Latin American countries was carried out in order to understand the need for its recognition in the legal system of each State.

To this end, after identifying its constitutional recognition, the object, scope of protection and procedural reality were analyzed on the basis of the study of the legal provisions and norms of each State; as well as, the development of its highest constitutional justice administration bodies, also known as the closing bodies in the mater.

In this sense, it was possible to recognized the rights that are mainly protected through this guarantee, such as freedom of movement, physical integrity, and life; however, there are related rights such as health and dignity, for example, that are also protected, which varies according to the state under analysis. Finally, in addition to establishing similarities and differences, it was possible to find some problems and challenges of habeas corpus and action for liberty, which, in a certain way, limit greater effectiveness in practice.

KEYWORDS: habeas corpus; liberty action; constitutional guarantee; action; typology; comparative analysis; challenges; jurisprudential development. 


\section{INTRODUCCIÓN}

T a Constitución de la República del Ecuador (CRE) desde su publicación en el Registro Oficial el 20 de octubre de 2008, ${ }^{1}$ reconoce inter alia diferentes garantías constitucionales como las normativas o abstractas, de políticas y servicios públicos, jurisdiccionales, y las institucionales. ${ }^{2}$ En este orden de ideas, estudiosos del derecho constitucional identifican, además, garantías sociales y democráticas. ${ }^{3}$

El paradigma constitucional y el proceso constituyente trajo consigo una innovadora Constitución, por cuanto, y entre otras cosas, se crearon y reformaron las garantías jurisdiccionales. En este punto es necesario recordar que la Constitución Política de la República del Ecuador (CPRE) de $1998^{4}$ reconocía únicamente al amparo, hábeas corpus y hábeas data como garantías jurisdiccionales; sin embargo, la CRE reconoció inicialmente las medidas cautelares, acción de protección, hábeas data, hábeas corpus, acceso a la información pública, acción por incumplimiento, acción extraordinaria de protección, para, posteriormente con la entrada en vigencia de la Ley Orgánica de Garantías Jurisdiccionales y Control Constitucional, reconocer la acción extraordinaria de protección contra decisiones de la justicia indígena ${ }^{5}$ (LOGJCC) y vía precedente jurisprudencial obligatorio ${ }^{6}$ a la acción de incumplimiento. ${ }^{7}$

1. Registro Oficial 449, 20 de octubre de 2008.

2. La Corte Constitucional para el Período de Transición realizó un programa de divulgación constitucional con la ciudadanía; para ello, elaboró a través del Centro de Estudios y Difusión del Derecho Constitucional (CEDEC), varias cartillas de divulgación, entre las cuales, se encuentra la n. ${ }^{\circ} 3$ sobre "Garantías Constitucionales", en la que se reconocen y establecen el objeto de las garantías institucionales.

3. Se puede citar a David Cordero Heredia y Marcelo Guerra Coronel.

4. Registro Oficial 1 de 11 de agosto de 1998.

5. Ecuador, Ley Orgánica de Garantías Jurisdiccionales y Control Constitucional, Registro Oficial 52,Suplemento, 22 de octubre de 2009, art. 65-6.

6. Ecuador Corte Constitucional, "Sentencia n. ${ }^{\circ}$ 001-10-PJO-CC", en el Caso n. ${ }^{\circ}$ 0999-09-EP, 22 de diciembre de 2010, 47.

7. Se puede identificar la evolución de esta garantía a partir de lo establecido en los artículos 82-84 de las Reglas de Procedimiento para el Ejercicio de las Competencias de la Corte Constitucional para el período de transición (11 de noviembre de 2008), en la cual la acción de incumplimiento no era una garantía jurisdiccional, sino una acción autónoma a otras acciones. Esto fue ratificado en la primera sentencia de acción de incumplimiento signada con el n. ${ }^{\circ}$ 0001-09-SIS-CC. Posteriormente, la Corte Constitucional en la sentencia $\mathrm{n}^{\circ}{ }^{0}$ 0013-09-SIS-CC, reconoce a la acción de incumplimiento como una garantía, el efecto inter partes, influye para que no sea considerada como la sentencia hito en matera de garantías. Luego la entrada en vigencia de la Ley Orgánica de Garantías Jurisdiccionales y Control Constitucional ratifica la calidad de acción y no de garantía, por cuanto la ley supra, no la reconoce en el Título II específico de las garantías jurisdiccionales, sino en el TíTULO VI referente a incumplimiento de sentencias y dictámenes constitucionales. 
Una de las garantías al que el constituyente en Montecristi brindó especial interés fue el hábeas corpus. En el Ecuador nace como un derecho en el número 8 del artículo 151 de la Constitución Política de la República del Ecuador de 1929. Sin embargo, fue hasta la CPRE que se reconoce como garantía, puesto que las anteriores la reconocieron como derecho, ${ }^{8}$ otorgaba la competencia al alcalde del cantón en donde se encontraba privado de libertad de forma ilegal o arbitraria una persona; para ello, la autoridad tenía 24 horas para resolver. ${ }^{9}$ La apelación era de competencia del Tribunal Constitucional. Sin embargo, con la entrada en vigencia de la CRE, el objeto se amplía y ya no solo protege la libertad ambulatoria, sino, además, la integridad personal de las personas privadas de la libertad, la vida y otros derechos conexos.

En Colombia existen antecedentes en el artículo 186 de la Constitución Política del Estado de la Nueva Granada de 1832, posteriormente, en el artículo 23 la Constitución de 1886; sin embargo, aparece expresamente en los artículos 56-64 del Decreto 1358 de $1964 .{ }^{10}$ En 1971, a través del Código de Procedimiento Penal, se lo reconoce como derecho y recurso, sin posibilidad de impugnación. No obstante, la reforma a la norma supra, mediante decreto 50 de 1987, sienta las bases para el reconocimiento constitucional en 1991.

Por otra parte, en Bolivia a partir del referéndum popular del 11 de enero de 1931, se reconoce el recurso para el derecho a la libertad física, ${ }^{11}$ sin embargo, la Constitución de 1938 es la que por primera vez la reconoce constitucionalmente, ${ }^{12}$ mucho antes que el recurso de amparo (1967). ${ }^{13}$ Pero esta denominación permaneció vigente hasta la Constitución Política del Estado de 2004 (Ley de 13 de abril de 2004), por cuanto la actual Constitución Política del Estado Plurinacional de Bolivia de 2009 reconoce a la acción de libertad como una acción de defensa.

En este contexto, luego de analizar el ámbito de protección y procesal del hábeas corpus en Ecuador y Colombia, o acción de libertad en Bolivia, es importante identificar cuáles son los principales problemas que esta garantía, derecho o acción de defensa constitucional presenta. Para ello, luego de sentar bases históricas, el análisis

8. Constitución Política de la República del Ecuador de 1938, 1945, 1946, 1967 y 1979.

9. La Constitución y la Ley de Régimen Municipal, regulaban situaciones de detención arbitraria; en tanto que, la Ley de Control Constitucional para cuando la prisión exceda lo previsto en la ley.

10. Véase en: https://bit.ly/3d71JD5.

11. Alan E. Vargas Lima, "La evolución de la justicia constitucional en Bolivia. Apuntes sobre el modelo de control concentrado y plural de constitucionalidad", Anuario Iberoamericano de Justicia Constitucional, 20 (2016): 369-404, http://dx.doi.org/10.18042/cepc/aijc.20.13.

12. Alan E. Vargas Lima, "La Evolución del Pensamiento Constitucional a través de la Bibliografía Jurídica Boliviana", Rev. Fuent. Cong. [online], vol. 8, n. 35 (2014): 44-60, https://bit.ly/3hIC1Va.

13. Reynaldo Peters Arza en 1972 propuso hábeas corpus en papel higiénico, durante la dictadura del general Hugo Banzer. 
se realiza a partir del estudio de las diferentes disposiciones jurídicas y del desarrollo jurisprudencial de sus máximos órganos de cierre en la materia.

\section{ANTECEDENTES HISTÓRICOS}

Entre los antecedentes del hábeas corpus encontramos a la Tribuna Plebis con la cual se defendía a la plebe de los patricios. Posteriormente a través del ius auxilii se abogaba por patricios y plebeyos frente al abuso de magistrados, algo similar al amparo en nuestros días, con lo cual se otorgaba "protección personal a los perseguidos por las autoridades (ius auxililii)" ${ }^{14}$

Así mismo, el pretor tutelaris ${ }^{15}$ a través sel liberalibus causis en la época de los Severos ${ }^{16}$ se convertía en una especie de tutela respecto a la libertad, así como las Leyes de Velerio Publicola y la custodia libera. ${ }^{17}$

Sin embargo, es el homine libero el antecedente más conocido del hábeas corpus. El Pretor en el Digesto exigía "Quem liberum dolo malo retines, exhibeas", ${ }^{18}$ con lo cual se exhibía a la persona que ha sido detenida con dolo.

Por otra parte, en España tanto el Fuero de León de $1188^{19}$ como los greuges que se proponían en las Cortes para la reparación de los derechos vulnerados por las autoridades $^{20}$ son antecedentes muy interesantes. Pero el más cercano es el Proceso de Manifestación ${ }^{21}$ de personas ${ }^{22}$ con su naturaleza cautelar y reparatoria con legitimación

14. Eduardo Ferrer Mac-Gregor, Panorámica del Derecho procesal constitucional y convencional (Madrid: Marcial Pons, 2013), 52.

15. Rafael Hernández Canelo, Derecho Romano. Historia e Instituciones (Lima: Jurista editores, 2014 ), 130.

16. A decir de Wolfgang Kunkel: "En la época de los Severos, época clásica tardía de la jurisprudencia romana, la vinculación de los juristas de la ciudad de Roma con los emperadores y con la administración imperial se hace más estrecha aún y más clara que en la época clásica alta". Wolfgang Kunkel, Historia del Derecho romano, trad. Juan Miquel (Barcelona: Ariel, 1973), 130.

17. Domingo García Belaunde, "Los orígenes del hábeas corpus", Derecho PUCP 31 (1973): 49. https://doi. org/10.18800/derechopucp.197301.006.

18. Kriegel, Hermann, Osenbrüggen, Cuerpo del Derecho Civil Romano a doble texto traducido al castellano del latino. Primera Parte Digesto Tomo III (Barcelona: 1897), 471.

19. Domingo García Belaunde, "Los orígenes del hábeas corpus", Derecho PUCP 31 (1973): 48-59, https:// doi.org/10.18800/derechopucp.197301.006.

20. Víctor Fairen Guillén, "Represión de actividades contra fuero y libertades. El proceso de Greuges", en Antecedentes aragoneses de los juicios de amparo (Ciudad de México: UNAM, 1971), 63.

21. Sus precedentes son: Del Codex Theodosianus, Digesto, VIII Concilio de Toledo (683), en el derecho bávaro Lex Baiuvariorum, Fueros de Nájera, Jaca (1064), Tudela, Zaragoza y Daroca (1142). La figura del Justicia en Aragón, Fuero de Ejea (1265), por citar. Ibíd., 100-1.

22. Víctor Fairén Guillén, Antecedentes aragoneses de los juicios de amparo (Ciudad de México: UNAM, 1971), 84 . 
activa amplia, para recuperar la libertad cuando haya sido privada injustamente. Para Víctor Fairén Guillén "fue el equivalente del remedio anglosajón de hábeas corpus". ${ }^{23}$ Finalmente la Constitución de Bayona en el artículo 132 establecía quiénes y cómo incurren en crimen por la arbitraria detención. ${ }^{24}$

Por otra parte, en Inglaterra la Constitución de Clarendon reconoció libertades que garantizaban un debido proceso, la cual además tuvo una fuerte influencia en la reconocida Carta Magna de Juan sin Tierra de 1215, que, en sus cláusulas 39 y 40, inspiró la creación del hábeas corpus. ${ }^{25}$ Más adelante, la participación de Edward Coke en la redacción de la Petition of Right de 1628 es crucial. Sin embargo, es en 1640 cuando el Habeas Corpus Act reconoce que cualquier persona puede solicitar cuando haya sido privado de su libertad por orden del rey o del Consejo. Luego de varias reformas, en 1679 el Habeas Corpus Amendment Act regula por primera vez un procedimiento de un proceso constitucional. ${ }^{26}$

En el mismo orden de ideas, en algunos países de Latinoamérica ocurrió algo similar por la colonización. En 1810 a las Cortes de Cádiz llegó la solicitud de don Manuel de Llano para la creación de una comisión redactora de la ley de hábeas corpus como la de Inglaterra, ${ }^{27}$ pero esta no prosperó, al igual que el proyecto Manifestaciones del hábeas corpus, propuesto por María Catalán en 1811. La Constitución de Cádiz de 1812 contenía disposiciones que prohibían al rey privar de la libertad a las personas. En el mismo año aparecería un documento conocido como los Elementos constitucionales circulados por el Sr. Rayón, en el cual se describía inter alia que toda Constitución debe contener la "célebre ley Corpus de Inglaterra". ${ }^{28}$

El primer país latinoamericano en reconocer el hábeas corpus en su ordenamiento jurídico fue Brasil ${ }^{29}$ en el Código Criminal de 1830, pero constitucionalmente lo hizo en 1891. En este sentido, se sumaron Chile en 1833, Guatemala en 1837, El Salvador

23. Víctor Fairén Guillén, “Comentarios a la Constitución de 1978: el 'hábeas corpus’ del artículo 17-4 y la manifestación de personas", Revista de administración pública, n. ${ }^{\circ} 88$ (1979): 9.

24. Francisco Astarloa Villena, "Los derechos y libertades en las constituciones históricas españolas", Revista de Estudios Politicos, n. ${ }^{\circ} 92$ (1996): 207-50, https://bit.ly/3dktrJy.

25. Dan Jones, Magna Carta. The making and legacy of the great charter (London: Head of Zeus, 2014), 100.

26. Eduardo Ferrer Mac-Gregor et al., Héctor Fix-Zamudio y el origen cientifico del derecho procesal constitucional (Managua: Corte Suprema de Justicia de la República de Nicaragua, 2010), 109.

27. Jorge Mario García Laguardia, "Las garantías jurisdiccionales para la tutela de los derechos humanos en Guatemala, hábeas corpus y amparo", en Garantías jurisdiccionales para la defensa de los derechos humanos en Iberoamérica, ed. Miguel López Ruiz (Ciudad de México: Universidad Nacional Autónoma de México. Instituto de Investigaciones Jurídicas, 1992), 315.

28. Instituto Nacional de Estudios Históricos de las Revoluciones de México, Elementos constitucionales circulados por el Sr. Rayón, https://bit.ly/2SxBMm2.

29. Juan Ignacio Tena Ybarra, "Evolución constitucional del Brasil", Revista de Estudios Políticos, n 31-32 (1947): 201-16, https://bit.ly/3do4JrW. 
en 1841, Costa Rica en 1859, Argentina en 1863, Honduras en 1865, Perú en 1879, Puerto Rico y Cuba en 1900, Panamá en 1904, Uruguay en 1918, Ecuador en 1929, Bolivia en 1938, Venezuela en 1947, Colombia en 1964, por citar unos cuantos países.

Tabla 1. Cronología sobre el reconocimiento latinoamericano del hábeas corpus/acción de libertad

\begin{tabular}{|l|c|c|}
\hline \multicolumn{1}{|c|}{ Estado } & Ley/Reglamento & Constitución \\
\hline Brasil & 1830 & 1891 \\
\hline Chile & $\mathrm{x}$ & 1833 \\
\hline Guatemala & 1837 & 1879 \\
\hline El Salvador & $\mathrm{x}$ & 1841 \\
\hline Costa Rica & $\mathrm{x}$ & 1859 \\
\hline Argentina & 1863 & 1949 \\
\hline Honduras & $\mathrm{x}$ & 1865 \\
\hline Perú & 1879 & 1920 \\
\hline Puerto Rico & 1900 & $\mathrm{x}$ \\
\hline Cuba & 1900 & 1901 \\
\hline Panamá & 1908 & 1904 \\
\hline Uruguay & $\mathrm{x}$ & 1918 \\
\hline Ecuador & 1933 & 1929 \\
\hline Bolivia & $\mathrm{x}$ & 1938 \\
\hline Venezuela & $\mathrm{x}$ & 1947 \\
\hline Colombia & 1964 & 1991 \\
\hline
\end{tabular}

Fuente: normativa estatal.

Elaboración propia.

\section{ÁMBITO DE PROTECCIÓN DEL HÁBEAS CORPUS: NATURALEZA, OBJETO Y DERECHOS TUTELADOS}

Por su naturaleza, en Ecuador el hábeas corpus es una garantía jurisdiccional de conocimiento, reconocida en el artículo 89 y 90 de la CRE y 43-46 de la Ley Orgánica de Garantías Jurisdiccionales y Control Constitucional; sin embargo, el desarrollo jurisprudencial de la anterior composición de la Corte Constitucional lo reconoce como derecho en la sentencia n. $^{\circ}$ 171-15-SEP-CC. 
Por el contrario, en Colombia, a más de ser una garantía constitucional,,$^{30}$ es una acción constitucional de conocimiento para tutelar la libertad, lo cual la convierte en un instrumento de protección de "otros derechos fundamentales como la integridad física y la vida de las personas privadas de la libertad". ${ }^{31}$ Así mismo, es un derecho fundamental según el artículo 30 de la Constitución Política de Colombia. ${ }^{32}$ Ahora bien, esto no significa que por considerar el hábeas corpus como acción, este pierde su carácter de derecho fundamental, al contrario, en él se hace efectivo. ${ }^{33}$

En similar sentido, la acción de libertad boliviana es reconocida en el artículo 125 de la Constitución Política del Estado Plurinacional de Bolivia como una acción de defensa tutelar, preventiva, correctiva y reparadora; ${ }^{34} \sin$ embargo, puede darse el caso de que al proponer la acción se dicten medidas cautelares. ${ }^{35}$

Ahora bien, identificada la naturaleza, es conveniente identificar el objeto del hábeas corpus y la acción de libertad. Según la $\mathrm{CRE}^{36}$ y la LOGJCC ${ }^{37}$ el hábeas corpus ecuatoriano tiene por objeto recuperar la libertad de la persona que fue privada de la misma de forma ilegal, ilegítima o arbitraria, ya sea por parte de un funcionario público o particular. Del mismo modo, es una garantía que se activa por tratos crueles, inhumanos o degradantes en contra de personas privadas de la libertad, por cuanto lo que pretende esta garantía es proteger su vida e integridad física, así como recuperar a la persona que ha sido desaparecida forzosamente. ${ }^{38} \mathrm{En}$ tal virtud, no puede ser utilizada para modificar la sentencia condenatoria, peor aún como recurso.$^{39}$ En ese orden de ideas, los derechos protegidos son la libertad, vida, integridad persona ${ }^{40} \mathrm{y}$ demás

30. Colombia Corte Constitucional, "Sentencia C-187/06", en el expediente P.E. 025, 15 de marzo de 2006, https://bit.ly/3wKejgI.

31. Colombia Corte Constitucional, "Sentencia C-042/18", en el expediente D-11862, 16 de mayo de 2018, https://bit.ly/3fZq25k.

32. Colombia, Constitución Política de Colombia, Gaceta Constitucional número 114, 4 de julio de1991.

33. Colombia, Corte Constitucional, "Sentencia C-620/01", en el expediente D-3157, 13 de junio de 2001, https://bit.ly/3rgKCRW.

34. Bolivia Tribunal Constitucional Plurinacional de Bolivia, "Sentencia 0641/2011-R", en el expediente 2009-20518-42-AL, 3 de mayo de 2011, https://bit.ly/3dTOnXf.

35. Bolivia, Código Procesal Constitucional, Gaceta 392NEC, 5 de julio de 2012, art. 35.

36. Ecuador, Constitución de la República del Ecuador, Registro Oficial 449, 20 de octubre de 2008, art. 8990.

37. Ecuador, Ley Orgánica de Garantías Jurisdiccionales y Control Constitucional, Registro Oficial 52,Suplemento, 22 de octubre de 2009, art. 43-5.

38. El artículo 43 de la LOGJCC amplía su alcance.

39. Ecuador Corte Constitucional, "Sentencia n. ${ }^{\circ}$ 004-18-PJO-CC", en el Caso n. ${ }^{\circ}$ 0157-15-JH, 18 de julio de 2018, párr. 54.

40. Ecuador Corte Constitucional, "Sentencia n. ${ }^{\circ} 365-18-\mathrm{JH} / 21$ y acumulados", en el Caso n. ${ }^{\circ} 365-18-J H y$ acumulados, 24 de marzo de 2021, párr. 67-71. 
derechos conexos como la salud, ${ }^{41}$ la dignidad, ${ }^{42}$ la vida familiar, la privacidad, el libre desarrollo de la personalidad, la autonomía. ${ }^{43}$ Es preciso mencionar que, a diferencia de otros países como Perú y Bolivia, en Ecuador no existe una tipología extensa; sin embargo, la Corte Constitucional en la Sentencia n. ${ }^{\circ} 202-19-\mathrm{JH} / 21$ reconoce la existencia del hábeas corpus correctivo, con el cual se protegen los derechos conexos de las personas durante su privación de libertad, siempre y cuando las restricciones y limitaciones no "fueren razonables o si producen efectos o daños graves al titular de derechos". 44

Por su parte, en Colombia el hábeas corpus, a más de garantizar el derecho a la libertad personal, "permite controlar [...] el respeto a la vida e integridad de las personas, así como impedir su desaparición forzada, su tortura y otros tratos o penas crueles" ${ }^{45}$ En este sentido, el máximo órgano de tutela de derechos reconoció la doble modalidad de esta acción (reparador y correctivo) ${ }^{46}$ e insinuó el reconocimiento del hábeas corpus preventivo. ${ }^{47}$

Del mismo modo, la Constitución Boliviana, a través de la acción de libertad, reconoce que esta podrá ser solicitada para guardar "tutela a su vida, cese la persecución indebida, se restablezcan las formalidades legales o se restituya su derecho a la libertad. ${ }^{48}$ Sin embargo, es notable el desarrollo jurisprudencial del Tribunal Constitucional boliviano, ${ }^{49}$ por cuanto ha logrado desarrollar una tipología amplia de esta

41. Ecuador Corte Constitucional, "Sentencia n. ${ }^{\circ}$ 209-15-JH/19 y (acumulado)", en el Caso n. ${ }^{\circ}$ 209-15-JH y 359-18-JH (acumulado), 12 de noviembre de 2019, 45.

42. Ecuador Corte Constitucional, "Sentencia n. ${ }^{\circ}$ 017-18-SEP-CC", en el Caso n. ${ }^{\circ}$ 0513-16-EP, 10 de enero de 2018, 91-2.

43, Ecuador Corte Constitucional, "Sentencia n. . 202-19-JH/21", en el Caso n. ${ }^{\circ}$ 202-19-JH, 24 de febrero de 2021, párr. 89.

44. Ibíd.

45. Colombia Corte Constitucional, "Sentencia C-187/06", en el expediente P.E. 025, 15 de marzo de 2006, https://bit.ly/3a2DoK1.

46. Véase, además, la Ley 1095 de 2006: "Mediante la Sentencia C-187-06 de 2006, la Corte Constitucional efectuó la revisión previa del Proyecto de Ley Estatutaria n. ${ }^{\circ}$ 284/05 Senado y n. ${ }^{\circ}$ 229/04 Cámara, 'Por medio de la cual se reglamenta el artículo 30 de la Constitución Política', de acuerdo con el artículo 153 de la Constitución Política. Declaró EXEQUIBLE el proyecto de ley, por carecer de vicios de procedimiento". En: https://normograma.info/men/docs/pdf/ley_1095_2006.pdf.

47. Ibíd.

48. Bolivia, Constitución Política del Estado Plurinacional de Bolivia, Gaceta Oficial, 7 de febrero de 2009, art. 125.

49. Las sentencias 19/2018-S2 y 17/2019-S2 han establecido estándares con enfoque y perspectiva de género. A través de esta acción, se protege también el derecho de las mujeres y otros del grupo de atención prioritaria, a una vida libre de violencia. 
acción; es así que, existe la acción de libertad reparadora, ${ }^{50}$ preventiva (restringida), ${ }^{51}$ correctiva, instructiva, ${ }^{52}$ traslativa o de pronto despacho, ${ }^{53}$ e innovativa. ${ }^{54}$

Hasta aquí se ha podido analizar la naturaleza, carácter, objeto y ámbito de protección del hábeas corpus y la acción de libertad como garantía constitucional en Ecuador y acción en Colombia y Bolivia. Además, se identificaron las tipologías que han desarrollado y reconocido los máximos órganos de justicia constitucional.

Tabla 2. Cuadro comparativo de los derechos tutelados por el hábeas corpus/acción de libertad

\begin{tabular}{|l|c|c|c|}
\hline \multicolumn{1}{|c|}{ Derechos } & Bolivia & Colombia & Ecuador \\
\hline Vida & $\mathrm{x}$ & $\mathrm{x}$ & $\mathrm{x}$ \\
\hline Integridad personal/física/locomoción & $\mathrm{x}$ & $\mathrm{x}$ & $\mathrm{x}$ \\
\hline Libertad personal & $\mathrm{x}$ & $\mathrm{x}$ & $\mathrm{x}$ \\
\hline Libertad personal/Desaparición forzada & $\mathrm{x}$ & $\mathrm{x}$ & $\mathrm{x}$ \\
\hline Salud/detenciones & - & - & $\mathrm{x}$ \\
\hline Dignidad & $\mathrm{x}$ & $\mathrm{x}$ & $\mathrm{x}$ \\
\hline Otros derechos conexos & $\mathrm{x}$ & $\mathrm{x}$ & $\mathrm{x}$ \\
\hline
\end{tabular}

Fuente: normativa estatal y jurisprudencia del Tribunal Constitucional Plurinacional de Bolivia, Corte Constitucional de Colombia y del Ecuador.

Elaboración propia.

\section{ÁMBITO PROCESAL}

En Ecuador, considerando el carácter actio populari de esta garantía, la legitimación activa es amplia y se encuentra en cualquier persona o grupo de personas a las que se le haya vulnerado uno o más de los derechos descritos supra, sin perjuicio de su

50. Bolivia Tribunal Constitucional Plurinacional de Bolivia, "Sentencia SCP 1156/2013", en el expediente 03362-2013-07-AL, 26 de julio de 2013.

51. Bolivia Tribunal Constitucional Plurinacional de Bolivia, "Sentencia SC 0044/2010-R", en el expediente 2007-16521-34-RHC, 20 de abril de 2010, https://bit.ly/3wMU3Lh.

52. Bolivia Tribunal Constitucional Plurinacional de Bolivia, "Sentencia 1156/2013", en el expediente 033622013-07-AL, 26 de julio de 2013, https://bit.ly/3heMExp.

53. Ibíd. Además, véase acción de libertad correctiva SCP 0865/2017-S1 de 2 de agosto de 2017. Acción de libertad preventiva SC 0044/2010-R de 20 de abril de 2010. Acción de libertad traslativa o de pronto despacho SCP 0239/2018-S2 de 12 de junio de 2018. Acción de libertad instructiva SCP 1156/2013 de 26 de julio de 2013.

54. Bolivia Tribunal Constitucional Plurinacional de Bolivia, "Sentencia SCP 1887/2014", en el expediente 06493-2014-13-AL, 25 de septiembre de 2014, https://bit.ly/3d8vGAg. 
nacionalidad; ${ }^{55}$ así mismo, puede ser propuesta por terceros interesados considerando que no siempre el accionante es el afectado. Del mismo modo, pueden accionar la Defensoría Pública y Defensoría del Pueblo, por mandato constitucional; constituyéndose como garantías institucionales que caracterizan el Estado constitucional de derechos y justicia.

Por su parte, en Colombia la legitimación activa tiene un carácter amplio para la proposición de esta acción constitucional, por cuanto, según la Ley 1095 de 2006, puede ser propuesto por la persona que se encuentra ilegalmente privado de su libertad o afectada, así como por terceros, como la Defensoría del Pueblo y la Procuraduría General de la Nación sin que medie mandato alguno para proponer la acción. ${ }^{56}$

Del mismo modo, en Bolivia se trata de una actio popularis con legitimación amplia, por cuanto el Código Procesal Constitucional permite que sea propuesta por el afectado, cualquier persona, la Defensoría del Pueblo y la Defensoría de la Niñez y Adolescencia. ${ }^{57}$

A propósito de la legitimación pasiva, en Ecuador esta acción podrá ser propuesta en contra de la persona o grupo de personas del sector público o privado ${ }^{58}$ que realicen la detención ilegal, ilegítima o arbitraria; así como también en contra de la o las personas que vulneren derechos de personas privadas de la libertad ${ }^{59}$ y al máximo representante de la Policía Nacional y ministro competente en casos de desaparición forzada.

Algo similar ocurre en Colombia, pues la acción se puede proponer en contra de las personas que realizan o autorizan la detención ilegal o arbitraria, ${ }^{60} \mathrm{o}$ que incurrieron en actos de desaparición forzada y delitos contra la vida. La norma normarum o la Ley Estatutaria no establecen expresamente la legitimación pasiva. En cuanto se refiere a la procedencia en contra de particulares, la Corte colombiana estableció que "por el desarrollo de los fenómenos sociales se pueden presentar abusos en este campo que

55. La Corte Constitucional del Ecuador en la sentencia 159-11-JH/19 hace referencia a las personas en situación de movilidad, en la cual se aclara este punto.

56. Colombia, Ley 1095 de 2006, Diario Oficial n. ${ }^{\circ}$ 46.440, 2 de noviembre de 2006, art. 3.

57. Véase el artículo 48 del Código Procesal Constitucional.

58. La Corte Constitucional del Ecuador en la sentencia 166-12-JH/20, analizó el hábeas corpus en contra de particulares.

59. Vida, integridad física, salud, dignidad, entre otros derechos conexos.

60. Colombia Corte Constitucional, "Sentencia C-042/18", en el expediente D-11862, 16 de mayo de 2018, https://bit.ly/3xMzKxJ. 
pueden ser corregidos excepcionalmente por el Hábeas Corpus, y residualmente por la acción de tutela". ${ }^{61}$

En el mismo orden de ideas, la legitimación pasiva no se encuentra expresamente en algún cuerpo normativo, sino a partir del desarrollo jurisprudencial del Tribunal Constitucional Plurinacional, el cual señaló que se puede proponer en contra de "particular o servidor público, sea este jurisdiccional o de apoyo judicial, e incluso de orden administrativo, cual podrían ser funcionarios policiales o del régimen penitenciario". ${ }^{62}$

En cuanto a la competencia, en Ecuador se rige conforme lo dispuesto en los artículos 7, 44, 167-169 de la LOGJCC; en consecuencia, el juez competente será cualquier juez - por sorteo- del lugar en donde se produjo la detención, en donde se encuentre privado de la libertad, o inclusive en el último domicilio del desaparecido o accionante. ${ }^{63}$ Sin embargo, es necesario identificar si dicha acción es competencia de juzgados y tribunales ${ }^{64}$ Corte Provincial, ${ }^{65}$ y Corte Nacional de Justicia inter alia, por razones de fuero. ${ }^{66}$

En el caso colombiano, la Ley 1095 regula el hábeas corpus y establece que son competentes para resolver esta garantía todos los jueces y tribunales de la rama del Poder Público: y, en caso de proponerse ante una corporación, se deberá tener a cada integrante como juez individual para resolver la acción planteada. Además, en caso de que el juez asignado con la presente acción ya la ha conocido deberá declararse impedido y enviarlo de inmediato al municipio más cercano de su misma jerarquía para seguir con la tramitación. ${ }^{67}$ Así mismo, la Sentencia C-187 de 2006 faculta en virtud de la jurisdicción en el lugar en donde ocurrieron los hechos respecto de la privación de libertad, o el lugar en donde la persona se encuentre privada de su tránsito. ${ }^{68}$

De igual modo, la sentencia del Tribunal Constitucional Plurinacional, SCP 0100/2019-S2, señala que la acción puede ser propuesta en el mismo lugar en donde

61. Colombia Corte Constitucional, "Sentencia C-010/94", en el expediente D-352, 20 de enero de 1994, https://bit.ly/3wGPHWl.

62. Colombia Corte Constitucional, "Sentencia C-0427/94", en el expediente 07312-2014-15-AL, 29 de abril de 2015, https://jurisprudenciaconstitucional.com/resolucion/2313-sentencia-constitucional-plurinacional-0427-2015-s2.

63. La Corte Constitucional del Ecuador en la sentencia 002-18-PJO-CC, prevé esa posibilidad.

64. En caso de no existir procesos judiciales que motiven el hábeas corpus.

65. En caso de la existencia de procesos judiciales.

66. Ecuador Corte Constitucional, "Sentencia n. ${ }^{\circ}$ 239-15-SEP-CC", en el Caso n. ${ }^{\circ}$ 0782-13-EP, 22 de julio de 2015, 11-3.

67. Colombia, Ley 1095 de 2006, Diario Oficial número 46440, 2 de noviembre de 2006.

68. Colombia Corte Constitucional, "Sentencia C-187-06", en el expediente P.E. 025, 15 de marzo de 2006, https://bit.ly/3s8GPoH. 
se vulneró el o los derechos; así como, en el lugar donde se pueda acceder por cercanía territorial, que preste mejores condiciones de transporte y en el domicilio del afectado, cuando la conculcación del derecho haya ocurrido en un lugar distinto al de la residencia de quien presenta la acción. ${ }^{69}$ De igual manera, en la Ley n. ${ }^{\circ} 1104$, del 28 de septiembre de 2018, se crean las Salas Constitucionales que comparten a su vez competencia ${ }^{70}$ con los jueces y tribunales penales, para su resolución. ${ }^{71}$ Es importante indicar que estas salas están ubicadas en las ciudades capitales de los departamentos y tienen un rango de acción de veinte kilómetros, y pueden resolver cuestiones de municipalidades que se localicen dentro de esta distancia. ${ }^{72}$

En cuanto se refiere al procedimiento en la realidad ecuatoriana, luego del sorteo y avoco del juez competente, de conformidad con lo ordenado en el artículo 44 LOGJCC, se desarrollará la audiencia ${ }^{73}$ dentro de las veinticuatro horas siguientes al avoco de conocimiento conforme lo dispuesto en el artículo 14 de la norma ibíd. ${ }^{74}$ Una vez que han concluido las intervenciones, el juez de forma verbal dictará sentencia en audiencia, y tiene hasta 24 horas luego de finalizada la audiencia para notificarla por escrito a las partes intervinientes en el proceso. En cuanto a la apelación, esta se podrá solicitar en audiencia o hasta 3 días después de notificado por escrito de conformidad con lo dispuesto en el artículo 24 ibíd., para lo cual no se requiere o exige fundamentación. Dependiendo del proceso, se apelará en la Corte Provincial o Corte Nacional de Justicia, que tienen la potestad discrecional de convocar a audiencia o no.

Por su parte, el procedimiento establecido en Colombia dista mucho del ecuatoriano, por cuanto se convoca a audiencia dentro de las 36 horas al avoco de conocimiento de la acción. El juez puede realizar las inspecciones y diligencias que crea pertinentes, inter alia, entrevista con la persona privada de la libertad, incluso en el lugar en el que se encuentra. En caso de probarse la violación de los derechos constitucionales o legales, se ordenará su inmediata libertad mediante auto interlocutorio, contra el cual no procede recurso alguno; sin embargo, sí se puede impugnar la negativa de hábeas corpus dentro de los tres días siguientes. El juez tiene veinticuatro horas para enviar

69. Bolivia Tribunal Constitucional Plurinacional, Sentencia SCP 0100/2019-S2, en el expediente 263962018-53-AL, 5 de abril de 2019.

70. Bolivia, Ley $n .^{\circ} 1104$, Gaceta 1103NEC, 28 de septiembre de 2018, art. 1.

71. Bolivia, Código Procesal Constitucional, art. 32.

72. Ibíd., art. 3.

73. La audiencia se puede desarrollar en el lugar en el que se encuentra detenida la persona, según el artículo 44 de la LOGJCC.

74. Los amicus curiae podrán solicitar intervenir en la audiencia, hasta antes de dictar sentencia y de conformidad con lo dispuesto en el artículo 12 de la LOGJCC. 
el expediente al juez jerárquico superior, previo sorteo, luego de lo cual tiene tres días para dictar sentencia. No cabe otro recurso.

En tanto que la Ley del Tribunal Constitucional Plurinacional establece que, apenas avoca conocimiento el juez, Tribunal o Sala Constitucional, convoca a audiencia dentro de las veinticuatro horas siguientes, con la potestad de dictar medidas cautelares a del afectado. Luego de la citación, se desarrolla la audiencia (impostergable) y, al finalizar la intervención de las partes, se dicta sentencia de forma verbal. ${ }^{75}$ Cabe indicar que no existe la posibilidad de interponer recursos verticales, por cuanto, los únicos recursos que prevé la ley son los horizontales de aclaración, enmienda o complementación; ${ }^{76}$ lo único que puede ocurrir es que cualquiera de la salas del Tribunal pueden conocer y resolver en revisión.

Tabla 3. Cuadro comparativo del ámbito procesal

\begin{tabular}{|c|c|c|c|}
\hline Indicadores & Bolivia & Colombia & Ecuador \\
\hline Legitimación activa amplia & $\mathrm{x}$ & $\mathrm{x}$ & $\mathrm{x}$ \\
\hline Legitimación pasiva/Estado & $\mathrm{x}$ & $\mathrm{x}$ & $\mathrm{x}$ \\
\hline Legitimado pasivo/Particulares & $\mathrm{x}$ & $\mathrm{x}$ & $\mathrm{x}$ \\
\hline Todos los jueces & - & $\mathrm{x}$ & $\mathrm{x}$ \\
\hline Solo jueces y Tribunales penales & $\mathrm{x}$ & - & - \\
\hline Audiencia & $\mathrm{x}$ & $\mathrm{x}$ & $\mathrm{x}$ \\
\hline Audiencia en el lugar de privación & $\mathrm{x}$ & $\mathrm{x}$ & $\mathrm{x}$ \\
\hline Entrevista juez-detenidos & - & $\mathrm{x}$ & - \\
\hline Amicus curiae & - & - & $\mathrm{x}$ \\
\hline Sentencia/auto interlocutorio oral en audiencia & $\mathrm{x}$ & $\mathrm{x}$ & $\mathrm{x}$ \\
\hline Sentencia/auto interlocutorio escrita & $\mathrm{x}$ & $\mathrm{x}$ & $\mathrm{x}$ \\
\hline Recursos/impugnación horizontales & $\mathrm{x}$ & $\mathrm{x}$ & $\mathrm{x}$ \\
\hline Recursos/impugnación verticales & - & $\mathrm{x}$ & $\mathrm{x}$ \\
\hline Revisión & $\mathrm{x}$ & - & - \\
\hline
\end{tabular}

Fuente: normativa estatal y jurisprudencia del Tribunal Constitucional Plurinacional de Bolivia, Corte Constitucional de Colombia y del Ecuador.

Elaboración propia.

75. Bolivia, Ley del Tribunal Constitucional Plurinacional, Gaceta 149NEC, 4 de junio de 2019, art. 68.

76. Ibíd., art. 45 . 


\section{PRINCIPALES PROBLEMAS Y DESAFÍOS}

Luego del análisis de esta garantía, derecho y acción, se han podido identificar los siguientes problemas, que en algunos casos son y que en otros podrían llegar a ser comunes.

En Ecuador la falta de especialización de los jueces en materia procesal constitucional o de derechos humanos deja en riesgo la eficiencia y eficacia del hábeas corpus. Por otra parte, si su objeto es reparar, ¿cómo evitar la vulneración de derechos de las personas privadas de la libertad?, considerando que la medida cautelar no procede contra decisiones judiciales. Asimismo, la incertidumbre en torno al control constitucional es uno de los mayores problemas, por cuanto los jueces se encuentran en una encrucijada generada por la actual composición de la Corte Constitucional. Ahora bien, frente a la coexistencia del control concentrado y difuso, a partir de una lectura literal e integral de la CRE y de la línea jurisprudencial trazada, reconocer esa coexistencia y adoptar un sistema difuso exclusivo para garantías jurisdiccionales constitucionales, sería acertado por las características de las mismas. No menos importante es el error de realizar trasplantes jurídicos sin identificar la realidad de su sistema de garantías, lo cual genera conflictos entre ellas por el amparo de los derechos constitucionales.

En Colombia la falta de normativización de la legitimación pasiva puede presentar un problema; sin embargo, el mayor reto es la especialización de los jueces en la materia, por cuanto todos los jueces y tribunales son competentes para resolver el hábeas corpus. Además, el incumplimiento de los plazos y términos es un mal común en la región.

En Bolivia la falta de apelación o reconocimiento de doble conforme es uno de los problemas que enfrenta la acción de libertad; sumado a esto, el incumplimiento de plazos y términos por la excesiva carga procesal, lo cual influye en el desarrollo de la audiencia, por cuanto se establecen conforme a la disponibilidad de fechas programadas en la agenda. Si bien es cierto que los jueces y tribunales penales son competentes para resolver la acción de libertad en cualquiera de sus tipos, eso no garantiza eficacia y eficiencia, por la diferencia normativa y axiológica existente entre justicia ordinaria y justicia constitucional.

Los problemas y desafíos que afronta esta garantía constitucional son comunes en Ecuador, Colombia y Bolivia, identificados desde la falta de juzgados especializados para la administración de justicia constitucional de la materia, el incumplimiento de plazos y términos, así como, el ambiguo desarrollo normativo del legislador positivo, que ha obligado al legislador negativo, desarrollar en el ámbito de sus competencias, soluciones frente a antinomias y lagunas. Asimismo, el amplio campo de protección 
del hábeas corpus o acción de libertad permite que tutelen derechos que otras garantías jurisdiccionales lo hacen.

Por ejemplo, en el caso ecuatoriano, la acción de protección (AP) es una garantía jurisdiccional constitucional que tiene por objeto reparar los derechos constitucionales y aquellos que se encuentran en instrumentos internacionales de derechos humanos, que han sido vulnerados por parte de autoridades públicas no judiciales o de aquellas que se encuentran identificados como sujetos pasivos en el artículo 41 de la LOGJCC; en consecuencia, a través de esta acción se podría reparar el derecho a la salud de las personas privadas de la libertad. Sin embargo, esta acción encuentra su límite en lo establecido por el legislador positivo y no por el constituyente, al señalar que la AP no procede cuando, inter alia, existe otra garantía que lo repara. A manera de corolario, el hábeas corpus es la acción de protección de las personas privadas de la libertad.

Del mismo modo, la medida cautelar (MC) constitucional tiene por objeto evitar o cesar la vulneración del derecho; sin embargo, nuevamente la limitación del legislador positivo influye para que no proceda contra decisiones judiciales, con lo cual abre la posibilidad del reconocimiento del hábeas corpus preventivo el cual asume la naturaleza preventiva de la MC.

Por otra parte, uno de los desafíos más grandes que tiene esta garantía jurisdiccional consiste en evitar que sea tratada como un recurso en materia penal, por cuanto se ha utilizado para recurrir de la sentencia condenatoria, por considerarla contraria a la ley, en algunos casos ilegítima o por lo general arbitraria. En este sentido, las cortes o tribunales deben ser cautelosos al interpretar y desarrollar jurisprudencia vinculante en la materia, ya que un excesivo ámbito de protección puede desnaturalizar la acción, así como también puede anular otras vías de jurisdicción ordinaria que son idóneas, eficaces y procesalmente correctas, como la apelación.

Así mismo, esta garantía posee una naturaleza actio popularis y no requiere de formalidades para su proposición; sin embargo, existe el riesgo que el legislador negativo a través de la jurisprudencia, establezca exigencias que imposibilitaría o dificultaría a cualquier persona o grupo de personas que no cuente con un profesional de la materia, la proposición de la misma; a lo cual se suma el desconocimiento de las dimensiones utilitarias por parte de las autoridades judiciales. Esto último, con base en la jurisprudencia del órgano de cierre, obligaría a la reforma permanente de la ley, la cual, falazmente, sí es conocida por todos. 
Tabla 4. Cuadro comparativo de problemas y desafíos

\begin{tabular}{|l|c|c|c|}
\hline \multicolumn{1}{|c|}{ Indicador } & Bolivia & Colombia & Ecuador \\
\hline Falta de juzgados especializados & $\mathrm{x}$ & $\mathrm{x}$ & $\mathrm{x}$ \\
\hline Incumplimiento de plazos y términos & $\mathrm{x}$ & $\mathrm{x}$ & $\mathrm{x}$ \\
\hline Ambiguo desarrollo normativo & $\mathrm{x}$ & $\mathrm{x}$ & $\mathrm{x}$ \\
\hline Seguridad jurídica & $\mathrm{x}$ & $\mathrm{x}$ & $\mathrm{x}$ \\
\hline Eliminación de autorrestricciones & $\mathrm{x}$ & - & - \\
\hline Solución de antinomias y lagunas & $\mathrm{x}$ & $\mathrm{x}$ & $\mathrm{x}$ \\
\hline $\begin{array}{l}\text { Control difuso de constitucionalidad en } \\
\text { materia de garantías jurisdiccionales }\end{array}$ & - & - & $\mathrm{x}$ \\
\hline Pugna de garantías/acciones & $\mathrm{x}$ & $\mathrm{x}$ & $\mathrm{x}$ \\
\hline Desnaturalización (recurso) & $\mathrm{x}$ & $\mathrm{x}$ & $\mathrm{x}$ \\
\hline Exceso de formalismos jurisprudenciales & $\mathrm{x}$ & $\mathrm{x}$ \\
\hline
\end{tabular}

Fuente: normativa estatal y jurisprudencia del Tribunal Constitucional Plurinacional de Bolivia, Corte Constitucional de Colombia y del Ecuador.

Elaboración propia.

\section{CONCLUSIONES}

La acción de hábeas corpus en Ecuador y Colombia y la acción de libertad en Bolivia comparten un similar ámbito de protección en favor de las personas privadas de la libertad por detenciones ilegales, ilegítimas o arbitrarias, así como en casos de desaparición forzada y demás derechos conexos. Para ello, se tuvo que recurrir a la jurisprudencia de los máximos órganos de administración de justicia constitucional, por cuanto, el desarrollo normativo es ambiguo. Cabe destacar que, en ninguno de los estados, se suspende por estados de excepción.

Como se anotó, la proposición de esta garantía constitucional es amplia, lo cual permite a cualquier persona ser el legitimado activo; sin embargo, la determinación del sujeto pasivo en Colombia es ambiguo, en contraste con lo que ocurre en Ecuador y Bolivia. Por su naturaleza, es rápida y sencilla, lo cual es importante por el bien jurídico tutelado; empero de ello, la práctica puede distorsionar la norma plasmada en la disposición jurídica. No obstante, pese al desarrollo de una audiencia y de la sentencia o auto interlocutorio que se dicte en y luego de la audiencia, se ha limitado el doble conforme en Bolivia. Del mismo modo, es necesario eliminar las autorrestricciones que encontramos en la jurisprudencia constitucional boliviana.

En este contexto, es importante fortalecer esta garantía jurisdiccional desde la identificación y proposición de soluciones; por cuanto, a más de ser un derecho, es una institución que tutela derechos conexos a la libertad ambulatoria. Esto implica un 
mejor desarrollo normativo y jurisprudencial con el objeto de evitar confusiones por contar con varias garantías que reparen el o los mismos derechos, a la hora de resolver. Es necesario que la justicia constitucional sea especializada y tomada en serio por todos, por cuanto la jurisprudencia es una fuente sociológica del derecho.

\section{BIBLIOGRAFÍA}

Belaunde, Domingo García. "Los orígenes del hábeas corpus”, Derecho PUCP 31 (1973): 4859. https://doi.org/10.18800/derechopucp.197301.006.

Bolivia. Tribunal Constitucional Plurinacional de Bolivia. "Sentencia 1156/2013". En el expediente 03362-2013-07-AL, 26 de julio de 2013, https://bit.ly/3heMExp.

—. Tribunal Constitucional Plurinacional. "Sentencia SCP 0100/2019-S2". En el expediente 26396-2018-53-AL, 5 de abril de 2019. https://bit.ly/3mDQkuS.

-. Tribunal Constitucional Plurinacional de Bolivia. "Sentencia 0641/2011-R". En el expediente 2009-20518-42-AL, 3 de mayo de 2011. https://bit.ly/3dTOnXf.

-. Tribunal Constitucional Plurinacional de Bolivia. "Sentencia SCP 1887/2014". En el expediente 06493-2014-13-AL, 25 de septiembre de 2014. https://bit.ly/3d8vGAg.

-. Tribunal Constitucional Plurinacional de Bolivia. "Sentencia SC 0044/2010-R". En el expediente 2007-16521-34-RHC, 20 de abril de 2010. https://bit.ly/3wMU3Lh.

Canelo, Rafael Hernández. Derecho Romano. Historia e Instituciones. Lima: Jurista editores, 2014.

Colombia. Corte Constitucional. "Sentencia C-187/06". En el expediente P.E. 025, 15 de marzo de 2006. https://bit.ly/3a2DoK1.

-. Corte Constitucional. "Sentencia C-042/18". En el expediente D-11862, 16 de mayo de 2018. https://bit.ly/3z6JSlm.

—. Corte Constitucional. "Sentencia C-010/94". En el expediente D-352, 20 de enero de 1994. https://bit.ly/3wGPHWl.

-. Corte Constitucional, "Sentencia C-0427/94". En el expediente 07312-2014-15-AL, 29 de abril de 2015. https://bit.ly/325C5Wj.

—. Corte Constitucional. "Sentencia C-187-06". En el expediente P.E. 025, 15 de marzo de 2006. https://bit.ly/3s8GPoH.

-. Corte Constitucional. "Sentencia C-187/06". En el expediente P.E. 025, 15 de marzo de 2006. https://bit.ly/3wKejgI.

-. Corte Constitucional. "Sentencia C-042/18". En el expediente D-11862, 16 de mayo de 2018. https://bit.ly/3fZq25k.

-. Corte Constitucional. "Sentencia C-620/01". En el expediente D-3157, 13 de junio de 2001. https://bit.ly/3Bactb3.

Ecuador. Corte Constitucional. "Sentencia n. ${ }^{\circ}$ 001-10-PJO-CC". En el Caso n. ${ }^{\circ}$ 0999-09-EP, 22 de diciembre de 2010. 
-. Corte Constitucional. "Sentencia n. ${ }^{\circ}$ 239-15-SEP-CC". En el Caso n. ${ }^{\circ}$ 0782-13-EP, 22 de julio de 2015.

- Corte Constitucional. "Sentencia n. ${ }^{\circ}$ 004-18-PJO-CC". En el Caso n. ${ }^{\circ}$ 0157-15-JH, 18 de julio de 2018.

- Corte Constitucional. "Sentencia n. ${ }^{\circ}$ 017-18-SEP-CC". En el Caso n. ${ }^{\circ}$ 0513-16-EP, 10 de enero de 2018.

- Corte Constitucional. "Sentencia n. ${ }^{\circ} 209-15-J H / 19$ y (acumulado)". En el Caso n. ${ }^{\circ} 209-15-$ JH y 359-18-JH (acumulado), 12 de noviembre de 2019.

-. Corte Constitucional. "Sentencia n. ${ }^{o}$ 166-12-JH/20". En el Caso n. ${ }^{o} 166-12-J H, 8$ de enero de 2020.

- Corte Constitucional. "Sentencia n. ${ }^{\circ}$ 202-19-JH/21". En el Caso n. ${ }^{o}$ 202-19-JH, 24 de febrero de 2021.

- Corte Constitucional. "Sentencia n. ${ }^{\circ}$ 365-18-JH/21 y acumulados". En el Caso n. ${ }^{\circ} 365-18$ JH y acumulados, 24 de marzo de 2021.

Guillén, Víctor Fairen. "Represión de actividades contra fuero y libertades. El proceso de Greuges". En Antecedentes aragoneses de los juicios de amparo. Ciudad de México: UNAM, 1971.

—. “Comentarios a la Constitución de 1978: el 'hábeas corpus' del artículo 17-4 y la manifestación de personas”. Revista de administración pública, n. ${ }^{\circ} 88$ (1979): 7-54.

Instituto Nacional de Estudios Históricos de las Revoluciones de México, Elementos constitucionales circulados por el Sr. Rayón, https://bit.ly/2SxBMm2.

Jones, Dan. Magna Carta. The making and legacy of the great charter. London: Head of Zeus, 2014.

Kriegel, Hermann y Osenbrüggen. Cuerpo del Derecho Civil Romano a doble texto traducido al castellano del latino. Primera Parte Digesto Tomo III. Barcelona: 1897.

Kunkel, Wolfgang. Historia del Derecho romano. Traducido por Juan Miquel. Barcelona: Ariel, 1973.

Laguardia, Jorge Mario García. "Las garantías jurisdiccionales para la tutela de los derechos humanos en Guatemala, hábeas corpus y amparo". En Garantías jurisdiccionales para la defensa de los derechos humanos en Iberoamérica, editado por Miguel López Ruiz (Ciudad de México: Universidad Nacional Autónoma de México. Instituto de Investigaciones Jurídicas, 1992.

Mac-Gregor, Eduardo Ferrer, et al. Héctor Fix-Zamudio y el origen cientifico del derecho procesal constitucional. Managua: Corte Suprema de Justicia de la República de Nicaragua, 2010.

- Panorámica del Derecho procesal constitucional y convencional. Madrid: Marcial Pons, 2013.

Vargas Lima, Alan E. "La evolución de la justicia constitucional en Bolivia. Apuntes sobre el modelo de control concentrado y plural de constitucionalidad". Anuario Iberoamericano de Justicia Constitucional, 20 (2016): 369-404, http://dx.doi.org/10.18042/cepc/aijc.20.13. 
—. "La Evolución del Pensamiento Constitucional a través de la Bibliografía Jurídica Boliviana". Rev. Fuent. Cong. [online], vol. 8, n. ${ }^{\circ} 35$ (2014): 44-60, https://bit.ly/3eqkcrI.

Villena, Francisco Astarloa. "Los derechos y libertades en las constituciones históricas españolas". Revista de Estudios Políticos, n. 92 (1996): 207-50, https://bit.ly/3dktrJy.

Ybarra, Juan Ignacio Tena. "Evolución constitucional del Brasil”. Revista de estudios politicos, $\mathrm{n}^{\circ}$ 31-32 (1947): 201-16, https://bit.ly/3do4JrW. 